\title{
Life Stressors, Emotional Avoidance and Breast Cancer
}

\author{
Violeta Cardenal ${ }^{1}$, Margarita Ortiz-Tallo², Isabel Martín Frías², \\ and Joaquina Martínez Lozano ${ }^{3}$ \\ ${ }^{1}$ Universidad Complutense (Spain) \\ ${ }^{2}$ Universidad de Málaga (Spain) \\ ${ }^{3}$ Clínica Ntra. Sra. de Belén de Murcia (Spain)
}

\begin{abstract}
Two groups of women were assessed in psychological aspects considered by some authors of interest for personal well-being. The sample consisted of 118 women, 58 diagnosed with breast cancer and 60 healthy women, of similar ages and personal circumstances. The purpose of the study was: (a) to explore the existence of stressful life events in the women's history and their degree of subjective distress and (b) to determine whether or not there is an emotional avoidance style in the group of women with breast cancer. The following assessment instruments were employed: the "Cuestionario de Formas de Afrontamiento" (CEA), the Five-Factor Inventory NEOPI-R, and the State-Trait Anger Inventory (STAXI). The results revealed more stressful vital events in the last two years in the group of women with breast cancer and significant differences in the degree of current distress. They also obtained higher scores in current anger, resignation, and neuroticism.
\end{abstract}

Keywords: breast cancer, adverse life events, emotional suppression

\begin{abstract}
Se ha realizado una evaluación de aspectos psicológicos a un grupo de 118 mujeres; 58 diagnosticadas de cáncer de mama y 60 mujeres sanas, de edades y situación personal similares. El estudio tiene como objetivos evaluar en la historia de las mujeres con cáncer de mama y comparar con el grupo de mujeres sanas: (a) la existencia de estresores vitales y su grado de malestar subjetivo y (b) rasgos de personalidad considerados característicos de un estilo de evitación emocional. Los instrumentos de evaluación utilizados son: el Cuestionario de Formas de Afrontamiento (CEA), el Inventario de Cinco Factores NEO-PI-R, y el Inventario Rasgo-Estado de Ira (STAXI). Los resultados encuentran, en el grupo de mujeres con cáncer de mama, mayor proporción de situaciones vitales estresantes durante los dos últimos años y diferencias significativas en el grado de malestar actual. También puntuaron más alto en las variables ira actual, resignación y neuroticismo.
\end{abstract}

Palabras clave: cáncer de mama, estresores vitales, evitación emocional

This study is part of a project entitled "Personality, Chronic Stress, and Health," funded by the Ministerio de Educación y Ciencia with the reference number BSO2002-00910.

Correspondence concerning this article should be addressed to Margarita Ortiz-Tallo, Facultad de Psicología, Campus de Teatinos s/n, 29071 Málaga (Spain). Phone: 952132555. FAX: 952131101. E-mail: mortiztallo@uma.es

Translation: Virginia Navascués Howard

How to cite the authors of this article: Cardenal, V., Ortíz-Tallo, M., Martín Frias, I. and Martínez Lozano, J. 
In this work, we address psychological aspects, such as the appraisal of the degree of distress produced by the experience of high-impact psychosocial stressors and the assessment of an emotional avoidance style, in women with breast cancer.

According to some health professionals, research has generally ignored women's particular details and has disregarded their complaints or needs, and their specific distress (Valls Llobet, 2005). Current research of health in the general population shows that women pay more visits to the doctor and they have more chronic problems, and these rates increase with age. Between the ages of 45 and 65 , women have more health problems because they have higher levels of daily stress and, in general, due to the higher family overload they bear in comparison to men. This is because the women still feel responsible for the care of their families, and this makes them more vulnerable to suffering and disease (Velasco Arias, 2005).

In this work, emotional factors and coping with stressful life events are considered fundamental, as they play a predominant role in the production of health-disease (Cano Vindel \& Miguel Tobal, 2001; Cardenal, 2001; Lieberman \& Goldstein, 2005; Sirgo, Díaz-Ovejero, Cano-Vindel, \& Pérez-Manga, 2001). It is well known that the study of emotions is quite difficult, especially because, in such analyses, complex processes that are interrelated within many variables must be separated.

In the decade of the 1970s, the discipline of PsychoOncology was updated, as a result of the research efforts of authors like James Holland (Holland \& Murillo, 2003). And as of 1980, it was reinforced due to psychologists' and psychiatrists' exchange of clinical observations of cancer patients' problems, thus creating the International PsychoOncology Society, in which information is exchanged about psychosocial variables, the immune system, its vulnerability, and cancer (López Martinez, 2003).

Following this line of interaction of factors, many authors have explored the relation of depression, affliction, anxiety, alexithymia, and emotional repression, as well as inadequate responses to stress with the onset and course of allergies, immune disorders, and cancer (Ader, Cohen, \& Felten, 1995; Contrada, Leventhal, \& O'Leary, 1990). Likewise, in some works, pessimism, depression, helplessness, and stressful life events have been noted to decrease immune competence and, consequently, to increase vulnerability to disease (Seligman, Walker, \& Rosenhan, 2001). General models, such as the psycho-immunological model (Watson \& Greer, 1983) and the explanatory model of the psychological influence in cancer (Contrada et al., 1990), have even been generated to explain this interaction.

This multidisciplinary approach justifies the appropriateness of studying the relations between psychosocial variables and breast cancer molecularly to provide empirical evidence within this more general molar, psycho-neuro-immunological approach to disease.
We wish to study in more detail two psychological aspects considered to be associated with the onset and course of breast cancer: (a) the influence of stressful life events and (b) the emotional avoidance style. With regard to the first factor, stressful life events such as the death of a loved one or the experience of some event involving a strong feeling of helplessness have frequently been observed in women with breast cancer (Butow et al., 2000; Cardenal, Sánchez-López, \& Ortiz-Tallo, 2005; Coe, Wiener, \& Levine, 1983; Ewertz, 1986; Greer \& Morris, 1975; Kwikstad, Vatten, Tretli, \& Kvinnsland, 1994; Yehuda, 2003).

Specifically, in the study of Ruiz, Bermúdez, Olivares, and Garde (1999), differences were observed in the presence of stressful life events occurring over the past two years between the group of women with breast cancer and the group of healthy women, not in the total sum of events, but rather in the type of events. Thus, the cancer patients had suffered a higher number of significant affective losses, such as the death of a loved one or divorce of their partner. More recently, in the meta-analysis of Garssen (2004), it is concluded, although with only slight empirical support, that a series of factors such as the loss of a loved one or insufficient social support may be associated with a poor cancer prognosis. However, other investigations do not seem to find any relation between breast cancer and various life stressors (Aro, De Konning, Schreck, Anttila, \& Pukkala, 2005; Ewertz, 1986; Chen et al., 1995; Sebastián Herránz, Mateos, \& Prado, 2000).

Other authors conclude that what ultimately determines the impact of life stressors on the health of women with breast cancer is the way they cope with such events (Chen et al., 1995; Cooper \& Faragher, 1993). It therefore seems appropriate to continue to provide more data that may add conclusions in one or the other direction. The impact of the stressful life event will be assessed through the degree of distress subjectively experienced by the person. Coping strategies used in the conflictive situation will also be analyzed.

The second aspect or factor that will be assessed in this work is the emotional avoidance style. This personality style is considered a broad and global category that includes several psychological dimensions. Among others, the following aspects are considered important within this style: repressive coping, emotional maladjustment, and the inhibition and repression of negative emotions (Cano-Vindel \& Miguel Tobal, 2001; Cano-Vindel, Sirgo, \& Pérez Manga, 1994; Cardenal, 2001; Cardenal \& Fierro, 2001; Contrada et al., 1990; Grassi, Rossi, Sabato, Cruciani, \& Zambelli, 2004; Iwamitsu et al., 2005a; Sánchez-López, 1999).

In the decade of 1980, the term Behavioral Pattern Type C (López Martínez, Esteve, Ramirez \& Anarte, 1998; Morris \& Greer, 1980; Temoshok \& Dreher, 1992) was coined with reference to cancer patients. It is the counterpart of Type A, which is used to describe the predisposition to coronary disease, and Type B, or healthy people. Type $\mathrm{C}$ refers to a 
coping style characterized by the repression of emotions and describes the Type $\mathrm{C}$ person as an "agreeable, selfsacrificing, cooperative, soothing, unassertive, patient, submissive individual, who does not express much negative emotion, particularly, anger," constituting an excess of rationality and anti-emotionality.

Watson and Greer (1983) specified that the suppression, more than repression, of negative emotions was one of the main aspects found in women with breast cancer, because although they were aware of their negative emotions, they suppressed them.

Contrada et al. (1990) subsequently classified the psychological factors related to cancer into two groups: the first includes depression, helplessness or hopelessness, and the loss of social support; the second one includes emotional avoidance, and has two main descriptors: low negative emotionality and high positive emotionality.

In the following years, various retrospective studies (Hahn \& Petitti, 1988) and the above-mentioned meta-analysis (McCaul, Sandgren, \& King, 1999) show that women with breast cancer present higher rationality, more emotional control, and less affective expressiveness than healthy women. Likewise, in groups of women psychologically assessed immediately after receiving the diagnosis of breast cancer, it was verified that the most consistent predictor of stress was avoidant coping. In this sense, women with this behavioral style suffered more distress throughout the course of the disease (Kenny, Carlon, McGuigan, \& Sheppard, 2000).

In the aforementioned review, Garssen (2004) notes that aspects such as the repression of negative emotions and hopelessness are the only psychological variables that have some influence on the onset and course of cancer, seeming to contribute to a poor prognosis. In the investigations of Iwamitsu et al. (2005a) with groups women diagnosed with breast cancer, they also conclude that the women who scored high in emotional avoidance style had more anxiety, more feelings of hopelessness, and more repressed anger throughout the course of the disease than did the women with the same diagnosis but who had an emotionally expressive style.

The reverse of this emotional avoidance style has been associated with better coping with cancer and with indicators of behavioral health. Thus, the expression of negative emotions, such as anger, is considered important for the person's integral well-being, and it can lead to a decrease in hostility, more self-confidence and assertiveness, as well as to predominantly positive affect (Greenberg \& Foerster, 1996; McCallum, Piper, \& Morin, 1995; Lieberman \& Goldstein, 2005).

In the area of psychological intervention, some classic studies (Moorey \& Greer, 1989, 2002; Moorey et al., 1994) should be mentioned, in which the importance of adjuvant psychological and cognitive therapy for cancer patients is stressed to promote the expression of negative emotions and a fighting spirit. Recent studies that also take these variables into account confirm that, after six months of participating in therapeutic groups that work with aspects such as favoring the experience of feelings of rage, women diagnosed with breast cancer had lower levels of depression and better quality of life (Iwamitsu et al., 2005b; Lieberman \& Goldstein, 2005).

Although we cannot currently state that emotional avoidance is a conclusive psychological factor in the etiology, prognosis, and course of breast cancer, we can proposealbeit with caution-that there is sufficient empirical evidence to warrant including this psychological variable in research designs on women with breast cancer in order to assess its contribution, however small, to the multifactorial etiopathogenia and evolution of this disease. Breast cancer is the most frequent type of neoplasia in the incidence of cancer and mortality of the female population and has become the second cause of death in women.

In this work, we propose the following hypotheses:

1. Women with breast cancer will have a higher degree of subjective distress related to the experience of life stressors than will women without breast cancer.

2. Women with breast cancer will present higher rates of the emotional avoidance personality style, characterized by more frequent use of repressive coping, higher emotional maladjustment, and more repression of negative emotions.

\section{Method}

\section{Participants}

The sample comprised a total of 118 women, 58 with breast cancer, mean age 49.9 years (range 40-60), the most frequent age being 48 years. Of this sample, $55 \%$ were married, $14.2 \%$ were single, $36 \%$ had two children, and $24.13 \%$ had no children. Regarding educational level, $48 \%$ had primary studies, $24.13 \%$ secondary studies, and $27 \%$ higher studies. With regard to work status, $52 \%$ worked outside of the home and the rest were housewives. They were selected from the patients of various Hospital Centers and from the "Association of Women who underwent Surgery for Breast Cancer" [in Spanish, abbreviated to ASAMMA] of Malaga.

We used the following inclusion criteria: (a) the women were of age and could read and write; (b) they were diagnosed with breast cancer and were not at a terminal stage of the oncological disease (stage IV); (c) they knew about their oncological diagnosis; (d) they had undergone partial or total surgery; (e) they were not currently receiving active cancer treatment (except for hormone treatment); (f) no longer than 2 years had gone by since they had completed the active treatment.

A control group $(n=60)$ made up of healthy women from the population of Malaga, was subsequently selected to match the experimental group in the socio-demographic variables of age and socio-cultural level. 


\section{Instruments}

A brief questionnaire with 6 sections was elaborated:

1. Sociodemographic data: age, civil status, educational level, number of children, and profession.

2. Data about negative stressful life events experienced in their childhood, and the amount of distress it caused them currently, on a scale ranging from 0 (little distress) to 10 (maximum distress).

3. Data about negative stressful life events experienced in the past two years, the time in months since they had experienced that situation, and the amount of distress it caused them in the past and currently, on a scale ranging from 0 (little distress) to 10 (maximum distress).

4. Emotional Repression and Resignation: We used two subscales from the "Cuestionario de Formas de Afrontamiento" (CEA; Rodríguez Marín, Terol, López-Roig, \& Pastor, 1992), which is the Spanish adaptation of the Ways of Coping Checklist (Folkman, Lazarus, Gruen, \& DeLongis, 1986). We wished to determine whether these factors appear with more intensity in women with breast cancer than in the control group. Emotional repression reflects rejection or avoidance of expressing feelings and/or thoughts to other people about a problem. Resignation may be one of the factors that indicate immobilization, which is why it is classified as avoidant. Its items express acceptance of or resignation about a problem. These two factors were used test the hypothesis about the influence of emotional repression/avoidance in the disease of breast cancer. The CEA has been shown to be a useful instrument to assess the ways that people cope with stress in a general population. The analysis of items, subscales, and total scores of the CEA indicate adequate reliability, and its convergent and discriminant validity have been judged fairly acceptable by means of correlations of the various factors with other measures of theoretically related variables. The structure of the instrument was established through factor analysis, which yielded 11 theoretically coherent and representative subscales of different ways of coping. The following factors are included: positive thoughts, blaming others, wishful thinking, seeking social support, seeking solutions, emotional repression, counting advantages, religiosity, and escape. In this study, we only administered the subscales of emotional repression and resignation.

5. Neuroticism. We used the Spanish adaptation (Cordero, Pamos, \& Seisdedos, 1999) of the entire Neuroticism Scale from the Five-Factor NEO-FFI, which is a reduced version of the NEO-Personality Inventory (NEO-PI-R; Costa \& McCrae, 1992). The Neuroticism Scale matches adjustment and emotional stability against emotional maladjustment. The general tendency to experience negative feelings, such as fear, melancholy, shame, anger, guilt, and disgust are the nucleus of this factor. Disorganized emotions interfere with adaptation, and people who suffer such emotions are more incapable of controlling their impulses and they cope worse with stress. Although people scoring high in the Neuroticism Scale of the NEO-FFI are more at risk for psychiatric problems, it actually measures a dimension of the normal personality. This scale has 6 subscales: Anxiety, Hostility, Depression, Social Anxiety, Impulsivity, and Vulnerability. The NEO-PI-R presents a brief measurement of the five main personality dimensions or factors (Neuroticism, Extraversion, Openness, Agreeableness, and Responsibility), and some of the most important traits that define each dimension. Each scale has six subscales. In all, the five main scales and the 30 partial scales of the NEO PI-R permit the global assessment of the adult personality.

6. Internal Anger Expression and External Anger Control. These scales were selected from the Trait-State Anger Inventory (STAXI) of Spielberger (1988). We used the Spanish version, adapted by Miguel Tobal, Casado, Cano-Vindel, and Spielberger (2001), which has six scales, five subscales, and an Anger Expression Index. The six scales are: State-Anger, Trait-Anger, External Anger Expression, Internal Anger Expression, External Anger Control, and Internal Anger Control. The Internal Anger Expression scale assesses the frequency with which feelings of anger are experienced but not expressed. People who score high in Internal Anger Expression experience intense feelings of anger, but they tend to suppress them rather than express them physically or verbally. The External Anger Control Scale assesses the frequency with which a person controls or avoids the expression of feelings of anger towards persons or objects from their environment. People who score high in External Anger Control usually use a lot of energy to foresee and prevent the experience and external expression of anger. Although such control over the external manifestations of anger may be desirable, when it is excessive, it can lead to passivity, depression, or giving up. This is why these scales were selected, as they are considered the most specific to assess emotional avoidance.

\section{Procedure}

First, we elaborated a work plan to select the variables of interest in order to test the hypotheses. We requested the pertinent authorizations from the Hospital Centers of Málaga, as well as from the ASAMMA to perform the investigations, and to have access to the patients diagnosed with breast cancer. We guaranteed anonymity, information, and support to the patients, as well as a complete report of the results of the investigation to the Hospital Centers. 
However bureaucracy, the difficulties in obtaining these authorizations, and the clinical reality forced us to reduce the assessment time to the minimum, and we decided to only include the fundamental variables. For this purpose, we chose very specific scales and subscales from the selected questionnaires to collect the data needed to contrast the hypotheses.

We guaranteed the least possible interference in the normal course of the hospital service, as well as the greatest consideration for the patients' physical and emotional status, which did not allow for performing long interviews or completing extensive questionnaires.

Most of the data were collected from patients already diagnosed and who were attended in the Psychological Services of the Centers, where a psychologist helped to complete the questionnaire without distorting or influencing the women's personal responses (only the patients who required some clarification to understand the items correctly).

\section{Results}

The comparisons of the breast cancer group and the control group in each of the goals of interest yielded the following results:

With regard to the first hypothesis, we carried out a $t$ test for independent groups. We chose this test because this study used a comparative design with two groups. In all cases, 1 and 117 degrees of freedom were used for the $T \mathrm{~s}$. First, we checked the variance homogeneity with Levene's $F$ test, which determines whether the variances of the two groups' scores in the dependent variables are equal. The results revealed no significant differences between the two groups in the degree of distress, either in childhood or in the last two years. However, as can be seen in Table 1 there was a significant difference in the group of women with breast cancer in the degree of distress produced by the current stressor $(p<.02)$. The percentage of women who reported having experienced stressful events in the last two years was also higher in the group of women with cancer than in the control group $(78.97 \%$ vs. $57.5 \%$, respectively). The same result was observed when participants were asked about the current stressor $(78.57 \%$ vs. $57.5 \%$, respectively).

Regarding the second hypothesis, a $t$-test for independent groups was performed to analyze the differences in repression-resignation, neuroticism, anger expression, and anger control in both groups. As above, we first verified the variance homogeneity with Levene's $F$ test.

As seen in Table 2, the results showed that there were statistically significant differences between the means of resignation $(M=7.16$ vs. $M=5.72, p<.001)$ and neuroticism $(M=22.82$ vs. $M=18.45, p<.018)$. People who score high in the resignation factor tend toward immobility, which is an avoidant style trait. In the Neuroticism Scale, a score of 22.82 is considered high and one of 18.45, medium. People who score high in neuroticism tend to experience negative feelings and to have irrational ideas, less control over their impulses, and to cope with stress worse than people who obtain lower scores (Costa \& McCrae, 2002). In the remaining variables-repression, anger expression, and anger controlthe results revealed no statistically significant differences between the two groups. Thus, in the group of women with cancer, there was a higher level of resignation and neuroticism than in the control group, but this was not observed in the variables of repression, anger expression, and anger control.

Table 1

Percentage of Women who Report Stressors, Means and Standard Deviations of Degree of Distress from Life Stressors and $t$-Values in the two Groups of Women

\begin{tabular}{|c|c|c|c|c|c|}
\hline \multirow{2}{*}{$\begin{array}{l}\text { Point in time of stressor/ } \\
\text { Group }\end{array}$} & \multirow{2}{*}{$\begin{array}{c}\text { Percentage of } \\
\text { Women reporting } \\
\text { Stressors }\end{array}$} & \multicolumn{4}{|c|}{ Degree of Distress } \\
\hline & & $M$ & $S D$ & $t$ & Significance \\
\hline \multicolumn{6}{|l|}{ Childhood stressor } \\
\hline Cancer Patients & 30.95 & 4.61 & 3.90 & \multirow{2}{*}{-0.73} & \multirow{2}{*}{.47} \\
\hline Control Group & 30 & 5.83 & 4.38 & & \\
\hline \multicolumn{6}{|l|}{ Stressor in past 2 years } \\
\hline Cancer Patients & 78.97 & 9.03 & 1.48 & \multirow{2}{*}{-.150} & \multirow{2}{*}{.88} \\
\hline Control Group & 57.5 & 9.08 & 1.23 & & \\
\hline \multicolumn{6}{|l|}{ Current stressor } \\
\hline Cancer Patients & 78.57 & 5.39 & 2.93 & \multirow{2}{*}{2.30} & \multirow{2}{*}{$.02 *$} \\
\hline Control Group & 57.5 & 3.60 & 2.70 & & \\
\hline
\end{tabular}

$* p<.05$. 
Table 2

Means and Standard Deviations and t-Value of the Emotional Avoidance Style in the two Groups of Women

\begin{tabular}{|c|c|c|c|c|}
\hline Variable / Group & $M$ & $S D$ & $t$ & Significance \\
\hline \multicolumn{5}{|l|}{ Repression of emotions } \\
\hline Cancer Patients & 11.018 & 3.830 & \multirow{2}{*}{0.875} & \multirow{2}{*}{0.383} \\
\hline Control Group & 10.519 & 2.735 & & \\
\hline \multicolumn{5}{|l|}{ Resignation } \\
\hline Cancer Patients & 7.169 & 2.501 & \multirow{2}{*}{3.567} & \multirow{2}{*}{$0.001 *$} \\
\hline Control Group & 5.721 & 1.921 & & \\
\hline \multicolumn{5}{|l|}{ Neuroticism } \\
\hline Cancer Patients & 22.827 & 10.705 & \multirow{2}{*}{2.400} & \multirow{2}{*}{$0.018^{*}$} \\
\hline Control Group & 18.458 & 7.322 & & \\
\hline \multicolumn{5}{|l|}{ Internal Anger Expression } \\
\hline Cancer Patients & 12.103 & 3.918 & \multirow{2}{*}{1.441} & \multirow{2}{*}{0.153} \\
\hline Control Group & 11.083 & 3.240 & & \\
\hline \multicolumn{5}{|l|}{ Anger Control } \\
\hline Cancer Patients & 17.258 & 4.681 & & \multirow{2}{*}{0.716} \\
\hline Control Group & 17.583 & 4.418 & & \\
\hline
\end{tabular}

$* p<.05$

\section{Discussion}

The present study investigated two aspects in a group of women with breast cancer: whether there was a higher level of distress related to the experience of life stressors and whether there was a higher degree of an emotional avoidance style. A group of female patients diagnosed with breast cancer was compared with a group of healthy women.

Regarding the first hypothesis, which stated that women with breast cancer would have a higher degree of subjective distress related to the experience of life stressors than healthy women, in the data of the women's history of stressful life events, we did not find that the proportion of women who reported having experienced particularly difficult life events in their childhood differed as a function of having breast cancer. However, a higher proportion of women with breast cancer did report having experienced an important life stressor (such as divorce of the death of a loved one) in the past two years. But all the women reported having experienced a high intensity stressing event $(9.03$ out of a maximum intensity of 10 ), so there were no differences in the degree of distress as a function of having breast cancer.

Likewise, the proportion of women who reported having experienced a current stressor was higher in the group of women with cancer. In this case, the degree of distress caused by the event varied in the expected direction, as the women with breast cancer reported a more negative impact. However, it should be taken into account that this is a retrospective study which collects data after the diagnosis.

These results are in accordance with some other studies that confirm that stressing life events could be related to cancer (Butow et al. 2000; Cardenal et al. 2005; Ewertz, 1986; Garssen, 2004; Greer \& Morris, 1975, Ruiz et al., 1999). We think that, in this exploratory work, the fact that we could not study in depth the history of each patient and their more painful memories may have affected the results. Some of the patients decided not to answer the questions about life stressors, saying they did not remember or that they were not in a position to recall them at that time. Therefore, the number of women who experienced stressing life events with a high degree of distress could be higher.

We also observed that the mean age of the women with cancer in our study coincides with the reports of current investigations about women's age and health. Between the ages of 45 and 65, there is an increase in chronic diseases (Velasco Arias, 2005; Valls Llobet, 2005), as during this developmental stage of women, they are more vulnerable to illnesses, due to biological aspects and to the higher family overload.

Regarding the second hypothesis, which proposed that women with breast cancer would have higher rates of emotional avoidant personality style, no significant differences were found in the factors of repressive coping, anger expression, and anger control (in other words, an emotional avoidant personality style). However, the women with breast cancer obtained significantly higher scores in the factors of resignation and neuroticism. Emotional adjustment or stability is contrasted with maladjustment or neuroticism, and although clinicians sometimes establish distinctions between different types of emotional disorders such as social phobia, agitated depression, or hostility, many studies have shown that people who have a tendency to one 
of these disorders also experience negative feelings such as fear, melancholy, shame, and guilt (Costa \& McCrae, 1992).

Resignation is classified by Rodríguez Marín et al. (1992) as an avoidant factor, because of its characteristic immobilization (Watson \& Greer, 1983) and these authors even include fatalism or stoic acceptance-whereby people consider that the disease does not depend on them and it is something they must resign themselves to-as a coping strategy to deal with the diagnosis. In some cases, acceptance is considered positive coping whereas in others, it can be considered an avoidant and negative strategy. Other works have examined patients' diverse reactions to diagnosis. Watson and Greer (1983) described five different psychological reactions to the diagnosis of breast cancer: denial, fighting spirit, fatalism, hopelessness, and anxious concern. These reactions are considered different ways of coping with the disease. However, when dealing with cancer, there is a high degree of consensus among authors that survival is higher when the person displays a fighting coping style instead of a resigned coping style (Bleiker et al., 1996; Cardenal, 2001; Greer \& Morris, 1975; Sirgo et al., 2001).

There is usually more anxiety and depression after the diagnosis in patients with an avoidant emotional style, because their level of chronic daily anxiety does not prepare them for high-impact stressors (Iwamitsu et al., 2005a, 2005b; Lieberman \& Goldstein, 2005). The results of this work partially agree with those of other authors, provided that resignation is included within the repressive coping style, and neuroticism is considered emotional maladjustment related to higher anxiety levels (Cardenal, 2001; SánchezLópez, 1999; Sandín, Chorot, Santed, \& Jiménez, 1994).

It is noteworthy that many patients diagnosed with breast cancer reported that it was very hard for them to respond to some of the items of the questionnaire; some of them even cried during the entire interview, or they could not go on responding. This reflects their pain and could also be an indication of the difficulty to express certain negative emotions.

This work has some important limitations, such as the fact that it is a retrospective study, in which all the women had previously been diagnosed with cancer. Future works should use a prospective design in which assessment is performed before the diagnosis, for example, when the women come to the hospital for a mammography, so their evolution could be followed, subsequently comparing the variables of interest in a longitudinal study.

The sample may have been biased because we only interviewed the women who had decided to consult the psychologist and this could be a group of patients who found it easier to seek help and, therefore, to express negative emotions.

Lastly, given these women's suffering and the difficulties to access their memories, we believe that unless assessment is included within a therapeutic intervention, it will be inadequate and limiting. Some authors are beginning to carry out and foresee intervention combined with research (Cruess, Antoni, \& McGregor, 2000; López Martínez, 2003; Yehuda, 2003). Thus, it would be desirable to include psychological treatment to assess women's needs, fears, and difficulties to express their feelings, so they can learn to seek help and improve their well-being and health at such a difficult and painful time of their lives. Self-help groups are also very useful, that is, groups in which women with cancer can share, learn more adaptive ways of coping with the disease and, especially, freely express their concerns and fears, which they sometimes do not allow themselves to express to their loved ones.

In future research, longitudinal studies should be carried out, in which the initial assessment is part of the psychological support, and the patients' way of coping with life stressors and the avoidant coping style are considered predictors of the evolution of the neoplasic disease. We believe that a psychological intervention that takes these aspects into account could enhance a more favorable prognosis and evolution of breast cancer.

\section{References}

Ader, R., Cohen, H., \& Felten, D. (1995). Psychoneuroinmunology: Interactions between the nervous system and the immune system. The Lancet, 345, 99-103.

Aro, A.R., De Konning, H.J., Schreck, M., Anttila, A., \& Pukkala, E. (2005). Psychological risk factors of incidence of breast cancer: A prospective cohort study in Finland. Psychological Medicine, 35, 1515 - 1521.

Bleiker, E., Ader, H.J., \& Van-Daal, W. (1995). Personality traits of women with breast cancer: Before and after diagnosis. Psychological-Reports, 76, 1139 -1146.

Bleiker, E., Van-der-Ploeg, H.M., Hendriks J.H., \& Ader, H.J., (1996). Personality factors and breast cancer development: A prospective longitudinal study. Journal National Cancer Institute, 20, 1478-82.

Butow, P.N., Hiller, J.E., Price, M.A., Thackway, S.V., Kricker, A., \& Tennant, C.C. (2000). Epidemiological evidence for a relationship between life events, coping style, and personality factors in the development of breast cancer. Journal of Psychosomatic Research, 49, 169-181.

Cano-Vindel, A., \& Miguel-Tobal, J.J. (2001). Emociones y salud. Ansiedad y Estrés, 7, 111-121.

Cano-Vindel, A., Sirgo, A., \& Pérez Manga, G. (1994). Cáncer y estilo represivo de afrontamiento. Ansiedad y Estrés, 0, 101112.

Cardenal, V. (2001). Estilos psicológicos y enfermedad física: variables psicosociales - el estilo de evitación emocional-y su influencia en el cáncer. Escritos de Psicología, 5, 36-52.

Cardenal, V., \& Fierro, A. (2001). Sexo y edad en estilos de personalidad, bienestar personal y adaptación social. Psicothema, 13, 118-126. 
Cardenal, V., Sánchez-López, M.P., \& Ortiz-Tallo, M. (2005). Impact on personality due to loss of or separation from loved ones. Journal of Loss and Trauma, 10, 267-292.

Chen, C.C., David, A.S., Nunnerley, H., Michell, M., Dawon, J.L., Berry, H., Dobbs A., \& Fahy, T. (1995). Adverse life events and breast cancer: Case-control study. British Medical Journal, $311,1527-30$.

Coe, C.L., Wiener, S.G., \& Levine, S. (1983). Psychoendocrine responses of mother and infant monkeys to disturbance and separation. In L. A. Rosenblum \& H. Moltz (Eds.), Symbiosis in parent-offspring interactions (pp. 189-214). New York: Plenum Press.

Contrada, R.J., Leventhal, H., \& O'Leary, A. (1990). Personality and health. In L.A. Pervin, Handbook of personality (pp. 638670). New York: Guilford Press.

Cooper, C.L., \& Faragher, E.B. (1993). Psychosocial stress and breast cancer: The inter-relationship between stress events, coping strategies, and personality. Psychological Medical, 23, 653-662.

Cordero, A., Pamos, A., \& Seisdedos, N. (1999). Inventario de personalidad NEO revisado (NEO PI-R): Inventario NEO reducido de cinco factores (NEO-FFI). Madrid: TEA Ediciones.

Costa, P.T. Jr., \& McCrae, R.R. (1992). The NEO-PI-R Personality Inventory manual. Odessa, FL: Psychological Assessment Resources [Spanish version: Neo PI-R, Inventario NEO Revisado (NEO-FFI). Madrid: TEA. 1999].

Costa, P.T. Jr., \& McCrae, R.R. (2002). Looking backward: Changes in the mean levels of personality traits from 80 to 12 . In D. Cervone \& W. Mischel (Eds.), Advances in personality science (pp. 219-237). New York: Guilford Press.

Cruess, D.G., Antoni, M.H., \& McGregor, B.A. (2000). Cognitivebehavioral stress management reduces serum cortisol by enhancing benefit finding among women being treated for early stage breast cancer. Psychosomatic Medicine, 62, 304-308.

Ewertz, M. (1986). Bereavement and breast cancer. British Journal of Cancer 53, 701-703.

Folkman, S., Lazarus, R.S., Gruen, R.J., \& DeLongis, A. (1986). Appraisal, coping, health status, and psychological symptoms. Journal of Personality and Social Psychology, 50, 571-579.

Garssen, B. (2004). Psychological factors and cancer development: Evidence after 30 years of research. Clinical Psychological Review, 24, 315-338.

Grassi, L., Rossi, E., Sabato, S., Cruciani, G., \& Zambelli, M. (2004). Diagnostic criteria for psychosomatic research and psychosocial variables in breast cancer patients. Psychosomatics 45, 483-491.

Greenberg, L.S., \& Foerster, F.S. (1996). Task analysis exemplified: The process of resolving unfinished business. Journal of Consulting and Clinical Psychology, 64, 439-446.

Greer, S., \& Morris, T. (1975). Psychological attributes of women who develop breast cancer: A controlled study. Journal of Psychosomatic Medicine, 19, 147-153.

Hahn, R.C., \& Petitti, D.B. (1988). Minnesota Multiphasic Personality Inventory-rated depression and the incidence of breast cancer. Cancer, 61, 845-848.
Holland, J. C., \& Murillo, M. (2003). Historia internacional de la psico-oncología. In M. Die Trill (Ed.), Manual de psicooncología (pp. 21-40). Madrid: Ades Editores.

Iwamitsu, Y., Shimoda, K., Abe, H., Tani, T., Okawa, M., \& Buck, R. (2005a). The relation between negative emotional suppression and emotional distress in breast cancer diagnosis and treatment. Health Communication, 18, 201-215.

Iwamitsu, Y., Shimoda, K., Abe, H., Tani, T., Okawa, M., \& Buck, R. (2005b). Anxiety, emotional suppression, and psychological distress before and after breast cancer diagnosis. Psychosomatics, 46, 19-24.

Kenny, D.T., Carlon, J.G., McGuigan, F.J., \& Sheppard, J.L. (2000). Stress and health: Research and clinical applications. Amsterdam: Harwood Academic Publishers.

Kvikstad, A., Vatten, L.J, Tretli, S., \& Kvinnsland, S. (1994). Death of a husband or marital divorce related to risk of breast cancer in middle-aged women. A nested case-control study among Norwegian women born 1935-1954. European Journal cancer, 30, 473-477.

Lieberman, M., \& Goldstein, B. (2005). Not all negative emotions are equal: The role of emotional expression in online support groups for women with breast cancer. Psycho-Oncology, 15, 160-168.

López Martínez, A.E. (2003). Hacer frente al cáncer. Archidona, Spain: Ediciones Aljibe.

López Martínez, A.E., Esteve, R., Ramirez, C., \& Anarte, M.T. (1998). Dimensionalización del contructo de Personalidad Tipo C. Psykhe, 7, 3-12.

López Martínez, A.E., Ramírez, C., Esteve, R., \& Anarte, M.T. (2002). El constructo Tipo C: una contribución a su definición a partir de datos empíricos. Psicología Conductual, 10, 229-249.

McCallum, M., Piper, W.E., \& Morin, H. (1995). Affect and outcome in short-term group therapy for loss. International Journal Group Psychoterapy, 43, 303-344.

McCaul, K., Sandgren, A.K., \& King, B. (1999). Coping and adjustment to breast cancer. Psycho-oncology, 8, 230-236.

Miguel-Tobal, J.J., Casado, M.I., Cano-Vindel, A., \& Spielberger, C.D. (2001). Inventario de Expresión de Ira EstadoRasgo-STAXI. Madrid: TEA Ediciones.

Moorey, S., \& Greer, S. (1989). Psychological therapy for patients with cancer. London: Heinemann Books.

Moorey, S., \& Greer, S. (2002). Cognitive behaviour therapy for people with cancer. Oxford, UK: Oxford University Press.

Moorey, S., Greer, S., Watson, M., Baruch, J., Robertson, M., Mason, A., Rowden, L., Tunmore, R., Law, M., \& Bliss, J. (1994). Adjuvant psychological therapy for patients with cancer: Outcome at one year. Psycho-Oncology, 3, 39-46.

Morris, T., \& Greer, S. (1980). A Type C for cancer? Low trait anxiety in the pathogenesis of breast cancer. Cancer Detection and Prevention, 3, Abstract 102.

Rodríguez-Marín, J., Terol, M.C., López-Roig, S., \& Pastor, M.A. (1992). Evaluación del afrontamiento del estrés: propiedades psicométricas del cuestionario de formas de afrontamiento de acontecimientos estresantes. Revista de Psicología de la Salud, 4, 59-84.

Ruiz, M. A., Bermúdez, J., Olivares, A., \& Garde, S. (1999). Factores psicosociales en el cáncer de mama: un estudio cuasiprospectivo. Boletín de Psicología, 64, 57-80. 
Sánchez-López, M.P. (1999). Temporalidad, cronopsicología y diferencias individuales. Madrid: Centro de Estudios Ramón Areces.

Sandin, B., Chorot, P., Santed, M.A., \& Jiménez, M.P. (1994) Stress behaviour types, personality, alexitimia, coping and state-trait anger expression. Stress News, 5, 3-9.

Sebastián Herránz, J., Mateos, N., \& Prado, C. (2000). Eventos vitales estresantes como factores de vulnerabilidad en el cáncer de mama. Ansiedad y Estrés, 6, 21-38.

Seligman, M.E.P., Walker, E.F., \& Rosenhan, D.L. (2001). Abnormal Psychology (4 ${ }^{\text {th }}$ ed.). New York: Norton.

Sirgo, A., Díaz-Ovejero, M., Cano-Vindel, A., \& Pérez-Manga, G. (2001). Ansiedad, ira y depresión en mujeres con cáncer de mama. Ansiedad y Estrés, 7, 259-271.

Spielberger, C.D. (1988). State-Trait Anger Expression Inventory (STAXI). Odessa, FL: Psychological Assessment Resources.
Temoshok, L., \& Dreher, H. (1992). The Type C connection. New York: Random House.

Valls Llobet, C. (2005). Las causas orgánicas del malestar de las mujeres. Mujer y Salud, 16, 5-10.

Velasco Arias, S. (2005). Síndromes del malestar de las mujeres en atención primaria. Mujer y Salud, 16, 11-15.

Watson, M., \& Greer S. (1983). Development of a questionnaire measure of emotional control. Journal of Psychosomatic Research, 27, 299-305.

Yehuda, R. (2003). Hypothalamic-pituitary-adrenal alterations in PTSD: Are they relevant to understanding cortisol alterations in cancer? Brain, Behavior and Immunity, 17, 73-83.

Received December 13, 2006

Revision received November 22, 2007

Accepted January 19, 2008 